\title{
No hope for the Irrelevance Claim
}

\author{
Miguel Egler $^{1}$ (D)
}

\begin{abstract}
Empirical findings about intuitions putatively cast doubt on the traditional methodology of philosophy. Herman Cappelen and Max Deutsch have argued that these methodological concerns are unmotivated as experimental findings about intuitions are irrelevant for assessments of the methodology of philosophy-I dub this the 'Irrelevance Claim'. In this paper, I first explain that for Cappelen and Deutsch to vindicate the Irrelevance Claim from a forceful objection, their arguments have to establish that intuitions play no epistemically significant role whatsoever in philosophy-call this the 'Orthogonality Claim'. I then argue that even under a charitable reading of their views Cappelen and Deutsch fail to establish the Orthogonality Claim. Lastly, I discuss empirical evidence that the Orthogonality Claim is false. The arguments in this paper will demonstrate that Cappelen and Deutsch cannot motivate the Irrelevance Claim and that their replies to recent experimental attacks on traditional methodology of philosophy do not succeed.
\end{abstract}

Keywords Experimental philosophy · Philosophical methodology · Intuition · Evidence

\section{Introduction}

Recent empirical studies suggest that people's intuitions are sensitive to a host of epistemically irrelevant factors-e.g., their culture, personality, and the order in which cases are presented to them (for a review: Machery $2017 \mathrm{ch}$. 2). These findings putatively raise concerns about the traditional methodology of philosophy,

Miguel Egler

me49@st-andrews.ac.uk

1 Arché Research Centre, University of St Andrews, 17-19 College St., St Andrews KY16 9AL, Scotland, UK 
which is commonly regarded to rely on appeals to intuition. Call this the 'experimentalist challenge'. Herman Cappelen and Max Deutsch have recently argued that this experimentalist challenge fails outright (Cappelen 2012; Deutsch 2015). Their argument for this conclusion rests on the (increasingly popular) view that intuitions do not play an evidential role in philosophy. I dub this view 'Intuition Denial' (henceforth ID). ${ }^{1}$ Both Cappelen and Deutsch contend that, given their arguments for ID, it naturally follows that:

Irrelevance Claim: Experimental findings about intuitions are simply irrelevant for assessments of the methodology of philosophy.

The central upshot of the Irrelevance Claim is that the experimentalist challenge turns out to be ultimately unmotivated.

In this paper I argue that Cappelen and Deutsch fail to establish the Irrelevance Claim. In the first part of the paper, I briefly discuss their arguments to the effect that the Irrelevance Claim follows from ID (Sect. 2), and then discuss a forceful objection to their proposal (Sect. 3). I then explain that this objection does not succeed outright as Cappelen and Deutsch's arguments for the Irrelevance Claim purport to motivate the following stronger claim:

Orthogonality Claim: Intuitions play no epistemically significant role whatsoever in philosophy.

In the second part of the paper, I survey the two main arguments Cappelen and Deutsch advance for ID and argue they cannot motivate the Orthogonality Claim (Sects. 4 and 5). Lastly, I discuss empirical evidence that suggests intuitions do play epistemically significant roles in philosophy—albeit not an evidential role (Sect. 6). This discussion will demonstrate that Cappelen and Deutsch's attempts to undermine the experimentalist challenge fail.

\section{Intuition denial and the Irrelevance Claim}

According to an influential conception of the methodology of philosophy, intuitions play a central role in philosophical inquiry. Typically, this proposal is fleshed out in terms of the claim that philosophers appeal to intuitions as evidence, and that philosophical claims consistent with widely-shared intuitions enjoy evidential support (see, e.g., Bealer 1998; Pust 2000). Despite its popularity, this intuitioncentred conception of the methodology of philosophy has come under sustained attack in recent years. Breaking with orthodoxy, some philosophers have argued that intuitions do not play an evidential role in philosophy (Lycan 1986; Williamson 2007; Cappelen 2012; Deutsch 2015). I have dubbed this view 'Intuition Denial' (ID).

Although proponents of ID all agree on what are the basic tenets of this view, they diverge significantly on what they take to be its motivations and its implications for debates about the methodology of philosophy. Cappelen and

\footnotetext{
1 This terminology is adapted from the one introduced by Nado (2016).
} 
Deutsch stand out amongst proponents of ID in at least two respects. First, their argument for this position relies on an innovative exegetical approach: they conduct a close and detailed reading of prominent philosophical texts to examine whether philosophers explicitly appeal to intuitions in support of philosophical positions and claims. This investigation effectively boils down to a project of identifying and cataloguing instances in which philosophers make claims of the sort ' $p$, because it seems true that $p$ '-which Cappelen and Deutsch take as indication that intuitions are being used in an evidential role. From this detailed examination, both Deutsch and Cappelen conclude that philosophers do not even purport to use intuitions as evidence. ${ }^{2}$

A second way in which Cappelen and Deutsch stand out from other proponents of ID is that they take their arguments for this view to motivate the Irrelevance Claim-i.e., the claim that findings about intuitions are irrelevant for assessments of the methodology of philosophy. In this sense, they contend that the following conditional holds:

ID/IC: If ID is true, then the Irrelevance Claim is true.

Cappelen is exceptionally clear in his endorsement of ID/IC. He claims that, given his arguments for ID, it then becomes obvious that

studies of intuitions people have about thought experiments have no direct relevance for philosophical arguments or theorizing. [...] In short: If philosophers don't rely on intuitions [as evidence], then the project of checking people's intuitions is philosophically pointless.

(Cappelen 2012, pp. 221-222) ${ }^{3}$

And on a similar note, Deutsch claims that

it really is simply a myth that philosophers employ a method, in reasoning about thought experiments and cases, whereby they make evidential appeals to intuitions. [...] As a result, the data collected by [experimental philosophers] in intuition surveys are mostly irrelevant to analytic philosophical method.

\section{(Deutsch 2015 xvi) ${ }^{4}$}

Deutsch seems to hedge commitment to the Irrelevance Claim when he states that empirical findings are "mostly irrelevant" to philosophical method. However, he clarifies that by "mostly irrelevant" he means that intuitions might be "relevant to philosophy in a broadly ethical way", as they could be "relevant to how we should treat others and how, more fundamentally, we should understand the social practices of different groups of people" (Deutsch 2015, p. 160). Moreover, Deutsch expresses

\footnotetext{
2 This differs from other arguments for ID, which maintain that philosophers appeal to intuitions as evidence, but that intuitions cannot play evidential roles.

3 Italics are mine.

4 Italics are mine.
} 
hope that his arguments for ID will bring attention to what he takes to be the useful facet of empirical findings about intuition-viz, these ethical considerations (Deutsch 2015, p. 161). In light of these claims, I contend that we can safely assume that Deutsch endorses ID/IC.

Now, it is quite clear that the Irrelevance Claim spells trouble for the experimentalist challenge. If findings about intuitions have no relevance for assessments of the epistemology of philosophy, then they fail to motivate any concerns about the methodology of philosophy. So, if Cappelen and Deutsch are right that ID/IC holds, then arguments for ID show the experimentalist challenge to be unmotivated.

\section{Objections to the Irrelevance Claim}

Attempts to motivate the Irrelevance Claim via arguments for ID have attracted much criticism in recent years. The most prominent of these replies seeks to establish that ID is simply false. Now, there is no shortage of ammunition for this line of reply. A quick survey of the recent literature reveals discontent with close to every aspect of Cappelen and Deutsch's attempts to establish ID (Chalmers 2014; Weatherson 2014; Weinberg 2014; Nado 2016; Climenhaga 2017; Brown 2017).

Both Cappelen and Deutsch have recently attempted to respond to some of these objections. This has animated a host of thorny debates on the merits and shortcomings of recent arguments for ID (see, e.g., Cappelen 2014; Deutsch 2017; Nado 2016, 2017). These discussions turn on complicated questions about the nature of evidence and what it means to appeal to evidence in philosophy. For the purposes of this paper I will sidestep all such debates and simply grant (for the sake of argument) that ID obtains and that proponents of ID can respond to the above criticisms-which I now set aside.

However, there is a second even more forceful line of reply that has gained prominence in recent years. According to this proposal, even if ID is true, this would still fall short of establishing the Irrelevance Claim-i.e., ID/IC is false. Key to this line of reply is the observation that questions about evidence do not exhaust all and every epistemically significant dimension of our practices of inquiry. Otherwise put, this amounts to the claim that beyond evidential roles, there are other roles of epistemic significance in philosophy. To explain this proposal, I will now clarify what I mean by an 'epistemically significant role'. I present the two most prominent uses of this notion in the recent literature and argue there is good reason to prefer one of them over the other (Sect. 3.1). I then detail the implications of this discussion for debates surrounding the Irrelevance Claim (Sect. 3.2).

\subsection{Epistemically significant roles}

On one common reading, 'epistemically significant role' refers to whatever puts one in a good epistemic standing to believe or judge a given proposition. This is the sense in which we should understand evidentialism to attribute a central epistemic role to evidence. Evidentialism states that the evidence one possesses determines which propositions one has epistemic justification to believe. Thus, evidence for 
$p$ will play a fundamental epistemic role insofar as it makes one justified to believe $p$.

Siegel and Silins (2015) appeal to this reading of an epistemically significant role in their discussion of the epistemology of perceptual experience. They suggest that perceptual experiences can play an epistemically significant role because they can make it rational for one to believe the contents of experience. And more recently, Smithies (2019) has argued that consciousness plays an epistemically significant role as the propositions one has justification to believe is determined by one's phenomenally individuated mental states.

On another prominent reading, 'epistemically significant role' refers to not only to what puts one in a good epistemic standing to believe or judge some proposition, but also to what directly bears on epistemic evaluations more broadly-including negative epistemic appraisals. ${ }^{5}$ This is the sense in which some have argued that intellectual vices such as wishful thinking play epistemically significant roles. Roughly put, the suggestion is that since such vices impede effective and responsible inquiry, their role in inquiry is epistemically significant (see, e.g., Cassam 2016). To illustrate, consider a case of wishful thinking: suppose I am wondering whether there is chocolate in the kitchen and, because I strongly wish there was, I come to believe as much. It is clear that the role my wishful thinking plays in forming the belief that there is chocolate in the kitchen is what makes this belief turn out unjustified. As such, the role this wishful thinking plays in my belief is presumably epistemically significant. In a similar vein, Ichikawa (2016) has argued that subconscious gender biases can play an epistemically significant role in hiring decisions. His suggestion is that because such biases can make hiring decisions irrational-since gender presumably has no bearing on whether one is a good job candidate-then the role they play in such decisions is thereby epistemically significant.

I will now argue that there are good reasons to endorse this second broader definition of an epistemically significant role over the first narrower one. To begin, recall the above case of wishful thinking. Note that on the narrow sense of what counts as an epistemically significant role-in which it captures only what puts one in a good epistemic standing to believe or judge some proposition-my wishful thinking about there being chocolate in the kitchen would be epistemically insignificant. After all, my wishful thinking cannot plausibly put me in a good epistemic standing to believe or judge there actually is chocolate in the kitchen. Likewise, the influence of subconscious gender biases in hiring decisions would also turn out to be epistemically insignificant on this narrow conception-as gender biases do not put one in a good epistemic position to make hiring decisions.

I propose that classifying the role of wishful thinking on belief-formation and of gender biases in hiring decisions as epistemically insignificant is untenable. This requires an overly restrictive conception of the 'epistemic' wherein this includes

\footnotetext{
5 Some might be concerned that this over-generates epistemic roles. I agree that it is difficult to demarcate the precise boundaries of what counts as an epistemic role in this broader definition; however, this paper focuses exclusively on what I take to be uncontroversial cases of epistemically significant roles. As such, we can set these concerns aside in what follows.
} 
only those things which contribute to putting one in a good epistemic standing to believe or judge propositions. However, this arbitrarily rules out many debates which are ordinarily taken to fall within the remit of epistemology: most notably, it regards questions about what contributes to negative epistemic appraisals of beliefs and judgements as not pertaining to epistemology. Lacking any reason to endorse this narrow conception of the epistemic, I contend that the second (broader) reading provides a more apt characterisation of what counts as an epistemically significant role. In line with this proposal, I adopt this broader reading in what follows.

\subsection{Epistemic roles, evidential roles, and the Irrelevance Claim}

In this section, I argue that adopting a broader reading of what counts as an epistemically significant role has important implications for debates surrounding the Irrelevance Claim. To do so, it will be useful to first point out that on this broader conception, some epistemic roles are clearly not evidential roles. To explain, consider the following case:

Errant: Psychological studies have discovered a pernicious cognitive bias that affects how people respond to a body of evidence E. This cognitive bias manifests in the tendency to inadvertently neglect certain propositions contained in $\mathrm{E}$, which then makes $p$ seem true. As $q$ clearly follows from $p$, people prone to this bias tend to infer $q$ when presented with E. But, there is simply no agreed upon answer as to what is the normatively correct response on whether $p$ given $\mathrm{E}$.

There are two noteworthy observations to make about Errant. The first is that the bias described in this case does not reasonably play an evidential role in inquiry about $q$. After all, facts about this bias do not speak in favour of either $q$ or not- $q$. At most, they show that people are likely to respond in certain ways on whether $p$ when presented with E. But, this is neither here nor there with respect to whether $q$ is true or not. Second, although the bias described in Errant does not play an evidential role in inquiry about $q$, it nevertheless does play an epistemically significant role in this line of inquiry (in the broader sense argued for above). For, the influence of this bias has direct bearing on the epistemic evaluation of beliefs one forms from inquiring into whether $q$. For instance, learning that one's belief that $q$ is caused by the bias described above would compel one to revise that belief. And, in this sense, this bias can reasonably be said to be epistemically significant.

With these considerations in mind, let us return to the discussion about ID/IC. What is important to note is that the considerations above suggest ID is compatible with a denial of the Irrelevance Claim. For, they indicate that even if it is true that intuitions do not play an evidential role in philosophy, they may still play some role of epistemic significance in philosophical inquiry. What could this non-evidential epistemically significant role of intuitions in philosophy be? We can cite here two prominent proposals on this issue.

The first is that, like the bias described in Errant, facts about what claims philosophers find intuitive can shape how they respond to the body of evidence available to them and determine what claims they come to believe (see, e.g., 
Ichikawa 2016). So, even if these intuitions are neither here nor there with respect to what is the evidence for a given proposition $p$, their role in belief formation about $p$ makes them epistemically significant. Another prominent proposal is that, analogous to how perceptual faculties are sources of perceptual evidence, and to how testimony is the source of testimonial evidence, intuition is a source of evidence for philosophical claims (Nado 2016, 2017). Thus, even if intuitions do not themselves play an evidential role in philosophy, they can still play the epistemically significant role of making evidence available to philosophers.

Now, if it is true that intuitions could play any of these (non-evidential) epistemically significant roles, then the ID/IC fails. For, if intuitions do play such epistemically significant roles in philosophy, then findings about intuitions are indeed relevant to assess the methodology of philosophy. This then suggests that arguments for ID fail to motivate the Irrelevance Claim (see, e.g., Ichikawa 2016; Nado 2016, 2017).

So, do the above proposals suffice to undermine Cappelen and Deutsch's arguments for the Irrelevance Claim? I contend that they do not. The main problem is that these proposals effectively beg the question against Cappelen and Deutsch by assuming that philosophers rely on intuitions in philosophical inquiry. For instance, Ichikawa's suggestion that intuitions influence what claims philosophers come to accept assumes the following is an accurate description of philosophical inquiry: a philosopher $\mathrm{S}$ has an intuition that $p$ and, because she has this intuition, she comes to believe or judge $p$. And Nado's claim that intuitions are a source of evidence describes philosophical inquiry as follows: a philosopher $S$ 's intuition that $p$ provides her with evidence that $p$, which she then relies on in philosophical inquiry. However, Cappelen and Deutsch argue that their exegetical analysis of prominent philosophical texts reveals that philosophers do not rely on intuitions in support of their philosophical positions and claims. Indeed, both Cappelen and Deutsch at points make explicit that their arguments should be taken to motivate the even stronger claim that intuitions do not play any role whatsoever in philosophy-I have previously dubbed this the 'Orthogonality Claim'. For example, Deutsch affirms that his arguments for ID show that all that matters for an assessment of a philosopher's epistemic standing with respect to her positions is whether the arguments she advances for them are correct (Deutsch 2015). Deutsch thus effectively suggests that considerations about whether those arguments are correct encompass all and every epistemically significant dimension of assessment of philosophical inquiry - thereby implying that intuitions cannot play any epistemically significant role in philosophical inquiry (cf. Deutsch 2017, pp. 426-427). And Cappelen explicitly suggests that his arguments for ID show that it is false that "[p]hilosophers rely (in some epistemically significant way) on intuitions when they make judgements about cases" (Cappelen 2012, p. 192). ${ }^{6}$

Now, it is noteworthy that there is one passage in which Cappelen seems to reject the Orthogonality Claim. At the end of his book he states that:

\footnotetext{
${ }^{6}$ Italics are mine.
} 
There's at least a pre-theoretically useful distinction between the context of discovery and the context of justification. This book has focused solely on the role of intuitions in the latter. I have said nothing about whether something that some philosophers would label 'intuition' could play a significant role in the context of discovery. It is not implausible that something reasonably labeled 'intuitive' can serve as a creative starting point for many cognitive activities, including philosophizing.

\section{Cappelen (2012, p. 230)}

On one reading of this passage, Cappelen is suggesting that intuitions may play some role of epistemic significance in philosophy. For, by leaving it open that intuitions play a role in the context of discovery, Cappelen would presumably accept that intuitions can shape philosophical theorising and thus influence which positions philosophers will come to hold. And, on a natural interpretation of this proposal, intuitions would turn out to play an epistemically significant role as they would have direct bearing on an epistemic evaluation of philosophers' warrant for holding those positions. For instance, if a philosopher finds out that she holds a position as a direct result of appealing to an epistemically deficient intuition in the context of discovery, then, plausibly, this would compel her to revise her belief in that position. Assuming Cappelen agrees with this verdict, then we should interpret his forceful claim that philosophers do not rely on intuitions 'in some epistemically significant way' differently: namely, as a more restricted claim about the role of intuitions in context of justification, which leaves it open they could play some other epistemically significant role in discovery.

Although seemingly plausible, I contend there are good reasons to reject this reading of the passage above. The reason is that Cappelen precedes the passage in question with the statement that he does not think it is "relevant to the questions under discussion [in the book]". In effect, Cappelen is saying that even if intuitions turn out to play a role in the context of discovery, he thinks this does not matter for the Irrelevance Claim, nor for his conclusion that checking people's intuitions is "philosophically pointless." I do not see how to square this statement with the reading in which Cappelen is open to the idea that intuitions could play an epistemically significant role in philosophy. For, if Cappelen took the potential role of intuitions in the context of discovery as epistemically significant, then surely he would regard them as relevant for an assessment of the methodology of philosophy. Given his explicit denial that he thinks this is the case, I maintain that we can safely regard Cappelen as a proponent of the Orthogonality Claim.

At this point, it is crucial to point out that the Orthogonality Claim effectively implies the Irrelevance Claim. For, if intuitions are in fact epistemically inert in philosophy, then empirical findings about intuitions simply cannot be relevant for debates about the methodology of philosophy. Thus, if Cappelen and Deutsch's arguments for ID could indeed motivate the Orthogonality Claim, they would thereby vindicate the Irrelevance Claim. For the remainder of this paper I assess whether this strategy for motivating the Irrelevance Claim is viable. In the subsequent sections, I survey the two main arguments Cappelen and Deutsch develop in support of ID and evaluate whether they could reasonably be taken to 
motivate the Orthogonality Claim. My conclusion is that they cannot. Building on these evaluations, I propose that Cappelen and Deutsch simply fail to establish the Irrelevance Claim, and that they cannot refute the experimentalist challenge.

\section{The argument from exegesis}

\subsection{The original argument}

The main argument Cappelen and Deutsch advance for ID claims that philosophical texts provide no reason to believe that philosophers use intuitions in an evidential role. To argue for this proposal Cappelen (2012) provides a detailed textual analysis of ten prominent philosophical thought-experiments, seeking to identify clear instances of appeals to intuitions in philosophical argumentation. To develop this approach, Cappelen first selects what he takes to be commonly-recognised "features of the intuitive": that is, tell-tale signs that demarcate intuition from other mental states. He then turns to philosophical texts to count how many times philosophers explicitly make reference to a mental state with these features in their writings. Deutsch (2015) takes on a very similar exegetical approach, conducting a close reading of what are perhaps the two most influential thought-experiments in recent analytical philosophy: Kripke's Gödel case against descriptivist theories of semantic reference, and Gettier's thought-experiments against the reductive analysis of knowledge in terms of justified true beliefs.

Cappelen and Deutsch both take their intuition-diagnostic procedures to show that the authors from the texts examined do not rely on intuitions as evidence. Moreover, both take their textual analyses as representative of the philosophical discipline as a whole. Thus, they contend that the conclusion they draw about the practices of philosophers from these few writings reveal that philosophers in general do not rely on intuitions in philosophical argumentation. More schematically:

\section{The Argument from Exegesis (AEx)}

P1 Textual analysis shows that philosophers do not make explicit appeals to intuitions in an evidential role.

P2 If philosophers do not make explicit appeals to intuitions in an evidential role, then intuitions do not play an evidential role in philosophy.

C Intuitions do not play an evidential role in philosophy. (ID)

The AEx has attracted a lot of criticism. We can divide these replies in two groups depending on which premise they reject. Most objections of the AEx target the first premise of this argument, by challenging what Cappelen and Deutsch regard as the 'diagnostic features of intuitions' - that is, those characteristics they take as distinctive of intuitions, and which they rely on to identify appeals to intuitions in philosophical texts. In particular, many suggest that these features are inadequate to demarcate intuitions from other mental states. This suggests that the textual analysis Cappelen and Deutsch provide may simply fail to establish that philosophers do not appeal to intuitions. 
Another prominent set of objections to the AEx raise doubts about its second premise. The central claim motivating these objections is the humdrum observation that we often fail to make explicit what is our evidence for many of the claims we make. For instance, if I assert that the prices of sardines in the supermarket have dropped, I might not state that I believe this because I saw the new prices on the supermarket shelf. But, just because I fail to make explicit that my perceptual evidence is what grounds my statement that sardines are cheaper on sale, this in no way demonstrates that I did not rely on that perceptual evidence when forming that belief. On a similar note, it seems plausible to say that even if philosophers do not make it explicit in their writings that they rely on intuitions as evidence for their positions and claims, this fails to rule out that they might be doing so after all (Nado 2016; Brown 2017).

I am sympathetic with the main idea of the above objections. But, as I have previously indicated, I will accept that Cappelen and Deutsch have successfully established ID. As such, I will assume they can somehow respond to these objections to the AEx. However, I maintain that the AEx still falls short of establishing the Irrelevance Claim. For, as I argued previously, the only way Cappelen and Deutsch could seek to vindicate the Irrelevance Claim is if their arguments could plausibly be taken to motivate the stronger Orthogonality Claimi.e., the claim that intuitions play no epistemically significant role whatsoever in philosophy. But, can we reasonably reformulate the AEx as a successful defence of the Orthogonality Claim? For the remainder of this section, I argue we cannot.

\subsection{The revised argument}

There are two ways to read the AEx such that it could purport to motivate the Orthogonality Claim. The first would require a reinterpretation of the second premise of this argument-i.e., the claim that 'If philosophers do not make explicit appeals to intuitions in an evidential role, then intuitions do not play an evidential role in philosophy'. To get the Orthogonality Claim off the ground, we could reinterpret it to read as 'If philosophers do not make explicit appeals to intuitions in an evidential role, then intuitions do not play any epistemically significant role whatsoever in philosophy.' Plugging this into the AEx would yield the following revised argument:

\section{Argument from Exegesis revised (AExr)}

P1 Textual analysis suggests that philosophers do not make explicit appeals to intuitions in an evidential role.

P2 If philosophers do not make explicit appeals to intuitions in an evidential role, then intuitions do not play any epistemically significant role in philosophy.

C Intuitions play no epistemically significant role whatsoever in philosophy. (Orthogonality Claim)

This argument is valid. However, I contend there are good reasons to resist the second premise of this revised version of AEx. To begin explaining, note that the second premise of the AExr virtually suggests that all that matters for an evaluation 
of the epistemology of philosophy are considerations about evidential support. The main problem for this proposal is that there does not seem to be any good reason to think that all debates about the epistemology of philosophy are reducible to questions about evidence. For instance, consider cases of beliefs caused by wishful thinking. Suppose that I form a belief that contextualism about knowledge is correct because I want my theory to work. Nobody would claim that wishful thinking of this sort is evidence for the belief that contextualism is correct; nevertheless, discovering that this is what caused my belief in contextualism provides decisive reasons to revise it. In this sense, it is quite clear that wishful thinking will be epistemically significant in philosophy, even though it is evidentially inert. If we are to take the AExr seriously (specifically its second premise), Cappelen and Deutsch would need to provide arguments to think this is not the case. As they provide no such arguments - and since none seem to be forthcoming-I take it there is no reason to endorse the AExr.

A second more promising way of revising the AEx so as to motivate the Orthogonality Claim would be to reinterpret its first premise-i.e., the claim that 'Textual analysis suggests that philosophers do not make explicit appeals to intuitions in an evidential role.' One way to reinterpret this premise would be to suggest that the textual analyses of Cappelen and Deutsch demonstrate not only that philosophers do not rely on intuitions in an evidential role, but that they do not rely on intuitions in any epistemically significant role whatsoever. This would then yield the following argument:

\section{Argument from Exegesis revised 2 (AExr 2)}

P1 Textual analysis suggests that philosophers do not make explicit appeals to intuitions in any epistemically significant role.

P2 If philosophers do not make explicit appeals to intuitions in an epistemically significant role, then there is no reason to think that philosophers ever appeal to intuitions in any epistemically significant role whatsoever in philosophical inquiry.

C Intuitions play no epistemically significant role in philosophy. (Orthogonality Claim)

The AExr 2 is also valid. However, I propose we have good reasons to reject its second premise. My objection echoes a reply to the original AEx (discussed earlier in this section). On this line of reply, an examination of whether philosophers explicitly mention appeals to intuitions in support of their claims is inadequate to identify whether they rely on intuitions in an evidential role. This reply begins with the humdrum observation that we don't often make explicit reference to what is the evidence for the claims we make. I may, e.g., believe that the prices of sardines in the supermarket have dropped because I saw their price tags on the shelves. This shows that even if I fail to note my perceptual evidence when I claim that the price of sardines have dropped, this does not show that I did not rely on my perceptual evidence after all. Furthermore, I submit that this line of reply naturally carries over to other roles of epistemic significance beyond evidential ones. For, just as we do not often make explicit what plays an evidential role in belief formation, we also often fail to note what plays other non-evidential roles of epistemic significance in 
such processes either. For example, suppose that a pernicious cognitive bias causes me to neglect certain propositions from a body of evidence $E$ when presented with $\mathrm{E}$, which in turn makes it seem to me that $p$ is true. Even if I do not make it explicit (or even recognise) that my judgement that $p$ was due to the influence of this cognitive bias, this does not show that this bias is thereby epistemically insignificant with respect to my judgement that $p$.

Now consider the case of intuitions in philosophy: suppose that I come to believe a proposition $q$ partly as a result of having an intuition that $q$ is true. What if $\mathrm{I}$ then come to rely on $q$ in philosophical theorising without mentioning that this is due to the fact that I find it intuitive? Does this show that my intuition that $q$ did not play an epistemically significant role in philosophical theorising? Presumably not. To buttress this proposal, imagine I find out that my intuition that $q$ stems from the operation of a problematic cognitive bias. This evidence would give me reason to revise not only my belief in $q$, but also my belief in any other claims that I infer from $q$. In this sense, examination of whether or not I mention having an intuition that $q$ in philosophical theorising is inadequate to assess whether that intuition plays an epistemically significant role in philosophical inquiry. This would then give us decisive reason to resist the second premise of the AExr 2.

In sum, I have discussed the two reinterpretations of the AEx which purport to motivate the Orthogonality Claim. However, I argued that these revised versions of the AEx fail. The first requires endorsing the controversial position according to which questions about evidence are all that matters to assess the epistemology of philosophical inquiry. But, as indicated above, this view is untenable. The second revised version suggests that the exegetical analysis Cappelen and Deutsch provide demonstrates that philosophers do not rely on intuitions in any epistemically significant role whatsoever. However, I have suggested that this exegetical approach is not suitable for this end, and cannot plausibly vindicate this claim. In conclusion, I submit that the most plausible revised versions of the AEx fails to motivate the Orthogonality Claim. As a result, they also fail to vindicate the Irrelevance Claimand cannot thus undercut the experimentalist challenge.

\section{The argument from alternative explanation}

\subsection{The original argument}

The central upshot of ID is that, despite what philosophers might think, they do not appeal to intuitions as evidence for their positions and claims. In effect, this amounts to the claim that philosophers are collectively mistaken about what practices they employ in the course of philosophical inquiry. It is noteworthy that this is quite a radical proposal. How could so many philosophers be mistaken about the practices central to their profession? This question make salient that ID is questionable lacking a supplementary picture to fill in the 'intuition-shaped hole' left in philosophers self-conception of their discipline.

Cappelen and Deutsch are both sensitive to this concern. Their second main argument for ID addresses this issue by attempting to provide an alternative picture 
of the epistemology of philosophy. For this aim, Cappelen and Deutsch once more make recourse to an exegetical approach that examines prominent philosophical writings. The purpose of this analysis is to identify that which philosophers offer as evidence for their views. To explain this proposal, it will be useful to provide one example of this approach. For this aim, I focus on what is perhaps the most detailed formulation of this alternative epistemological picture: namely, Deutsch's reconstruction of Gettier's 10 coin case.

Like most philosophers, Deutsch agrees that the correct verdict on the scenario described in that case is that Smith does indeed have a justified true belief that (e), yet does not know that (e). But, against orthodoxy, Deutsch objects that what justifies or provides evidence for this verdict is the fact that people are likely to have an intuition that Smith does not know that (e). For, Gettier nowhere makes explicit appeal to what is 'intuitive', or mention that we are supposed to have any particular 'intuition', as evidence for this conclusion. Rather, Deutsch points out, a textual analysis reveals that Gettier offers only the following argument in support of the verdict that Smith does not know that (e):

But it is equally clear that Smith does not know that (e) is true; for (e) is true in virtue of the number of coins in Smith's pocket, while Smith does not know how many coins are in Smith's pocket, and bases his belief in (e) on a count of the coins in Jones's pocket, whom he falsely believes to be the man who will get the job.

Deutsch argues further that if Gettier offered only this argument in support of the claim that Smith does not know that (e), then we should read him to regard that argument as the evidence for this claim. As such, Deutsch suggests that the correct interpretation of Gettier's writings is that he relies only on the above argument to provide evidential support to the conclusion that Smith does not know that (e).

Both Cappelen and Deutsch offer a similar verdict about all other philosophical texts they examine. In more detail, they first suggest that textual analyses reveal that the authors of these texts offer only arguments in support of the claims they advance. From this analysis, they suggest that those philosophers are relying on only those arguments as evidence for their positions and claims. Furthermore, Cappelen and Deutsch both suggest that these analyses are representative of the philosophical discipline as a whole. As such, they take an inductive step to then claim that philosophers in general rely only on arguments as evidence. Call this the 'Argument from Alternative Explanation' (AAE):

\section{Argument from Alternative Explanation (AAE)}

P1 Textual analysis reveals that philosophers offer only arguments as evidence for their philosophical positions and claims.

P2 If philosophers offer only arguments as evidence of their positions and claims, then they rely on only those arguments as evidence for their positions and claims.

C Philosophers rely only on arguments as evidence for their philosophical positions and claims. (ID) 
The AAE has also attracted a fair amount of criticism. For the most part, these objections have focused on the second premise of this argument - that is, the claim that philosophers rely only on arguments as evidence for their positions and claims. The main thrust of such replies is the claim that, even if philosophers offer only arguments as evidence, this still leaves it open that they rely on intuitions in an evidential role after all (Chalmers 2014; Weatherson 2014; Brown 2017). For instance, consider again the suggestion that a textual analysis reveals that Gettier offers only the above brief argument in support of his verdict on the 10 coin case. Even granting this much does not suffice to show what Gettier took to be evidence for the premises of that argument. At this point, a natural suggestion would be to say that Gettier took his intuitions to be evidence for those premises. Of course, Cappelen and Deutsch would deny this. But then, this pushes the burden of proof back onto them to show what is the evidence for those premises. In line with the AAE, we could entertain the hypothesis that Gettier just relied on even further arguments in support of such premises. But, it is clear that this in turn invites an infinite regress-with each of these arguments requiring another argument in support of their own premises. Again, a natural suggestion is that intuitions might come in at some point to end this justificatory chain. Given that the textual analyses that Cappelen and Deutsch offer cannot rule out this possibility, then they presumably fail to show that philosophers do not rely on intuitions in an evidential role after all.

Deutsch has recently attempted to respond to this line of reply (Deutsch 2015 chs. $4 \& 5)$. In a nutshell, his arguments amount to the claim that the challenge of accounting for the ultimate justifier is a problem for all philosophers-and, as he argues, even for all scientists. And so, he contends that it is not so clear that the burden of proof is on him to show that intuitions do not come in at any point in this justification chain, or even that they are unproblematic in case they actually do.

I will simply assume that Deutsch's response succeeds. The motivation for this is that, as I have indicated in the outset of this paper, I am here granting ID (just for the sake of argument). However, I submit that even if we grant the AAE, this argument cannot by itself establish the Irrelevance Claim. Again, the reason for this is that the AAE can at most provide support for ID; but, as I have argued, Cappelen and Deutsch must establish the Orthogonality Claim if they are to vindicate the Irrelevance Claim. So, can we revise the AAE so as to successfully motivate the Orthogonality Claim? For the remainder of this section, I will argue that we cannot.

\subsection{The revised argument}

The AAE easily lends itself to a charitable reading so as to motivate the Orthogonality Claim. The most promising of these readings requires a modification of the first premise of the AAE - that is, the claim that textual analysis reveals that philosophers offer only arguments as evidence for their philosophical positions and claims. On this alternative reading, the textual analyses provided by Cappelen and Deutsch demonstrate not only that philosophers offer exclusively arguments as evidence, but that these arguments are the single source of epistemic support they provide for their positions and claims. In other words, this would amount to the 
claim that all of the epistemic support these views receive come from such arguments. Furthermore, in line with Cappelen and Deutsch's exegetical approach, we can then conclude that philosophers rely only on such arguments as epistemic support for their claims. Note that this then plausibly implies that the epistemic standing of those positions and claims hinges exclusively on the arguments philosophers advance. As a consequence, it becomes hard to see what epistemically significant role intuitions could play in philosophy. That is:

\section{Argument from Alternative Explanation revised (AAEr)}

P1 Textual analysis suggests that philosophers offer only arguments in support of their philosophical positions and claims.

P2 If philosophers offer only arguments in support of their positions and claims, then they rely on only those arguments in support of their positions and claims.

P3 If philosophers rely on only arguments in support for their positions and claims, then the epistemic standing of their positions and claims depends exclusively on those arguments.

C Intuitions play no epistemically significant role in philosophy.

I submit there are good reasons to resist both the second and third premises of this argument. Let us start with the second premise-i.e., the claim that 'If philosophers offer only arguments in support of their positions and claims, then they rely only on those arguments as epistemological support for their positions and claims.' The objection I advance to this premise resembles a line of reply I discussed with regards to the AExr (see previous section). Again, the objection is that focusing on what philosophers explicitly offer in support of their claims is inadequate to determine what they rely on. For instance, we often don't make explicit reference to what is the evidence for the claims we make. We can advance a similar line of reply with respect to the second premise of the AAEr. Specifically, we can simply claim that because philosophers offer only arguments in support of their claims, this is insufficient to show that these arguments are all that they rely on as epistemological support for those claims. For instance, even if philosophers fail to mention that they endorse an argument because they find their premises intuitive, this does not mean that they do not rely on those intuitions as epistemological support for those arguments after all.

Let us now turn to the third premise of the AAEr-i.e., the claim that 'If philosophers rely only on arguments as support for their positions and claims, then the epistemic standing of their positions and claims depends exclusively on the arguments they advance.' It is not too hard to see that attempting to account for the epistemology of our philosophical practices exclusively in terms of the arguments philosophers advance invites some bad results. For instance, suppose that Gettier took the above argument to be correct because his astrologist read this off of his zodiac map. Presumably, it is less than rational to accept an argument because one believes in the power of the stars to deliver philosophical truths. In this sense, it seems false to assert that all that matters for an evaluation of Gettier's epistemic standing with respect to the claim that 'Smith does not know that (e)' is that he endorses a correct argument to this effect. Similarly, we can find fault in a student 
who believes Gettier's argument merely because she heard a professor claim that this argument is true. Presumably, this alone does not suffice to put her in a good epistemic standing with respect to the claim that Smith does not know that (e). For, unless she has good reasons to accept Gettier's argument for this conclusion, she could not be said to be in a sufficiently good position to endorse it. So, to a first approximation, it seems that focusing exclusively on the arguments a philosopher advances for her positions and claims would presumably fail to account for important dimensions of the epistemology of our philosophical positions and claims. After all, it would only seem reasonable to think that the reasons for which either Gettier or anyone else would have to hold these arguments to be true are an important feature of whether they are in a good epistemic standing to endorse. ${ }^{7}$

In light of these two objections, I submit that the AAEr fails. Against its second premise, I argued that an analysis of what philosophers explicitly offer in support of their claim is not reliable indication of what they actually relied on as epistemological support for those claims. Against the third premise, I argued that we cannot provide a satisfactory analysis of the epistemology of a philosopher's positions and claims by focusing exclusively on the arguments she advances for them. As such, I contend that the AAEr fails to motivate the Orthogonality Claim. As a consequence, it cannot motivate the Irrelevance Claim.

\section{Rebutting the Orthogonality Claim}

I have been arguing that Cappelen and Deutsch fail to motivate the Orthogonality Claim. However, it should be clear that even if the arguments developed so far are correct, they fall short of a rebuttal of the Orthogonality Claim. After all, I have not given any reason to think intuitions in fact play any epistemically significant role in philosophy. In this section, I argue that they do and that the Irrelevance Claim is thereby false.

Before proceeding, two clarifications are in order. First, following most recent metaphilosophical debates about intuitions, I adopt here a fairly minimal conception of intuitions according to which these are immediate, unreflective, pre-theoretic judgements that a proposition is true (for a discussion: Stich and Tobia 2016). It is however noteworthy that Cappelen (2012) raises doubts about the very category of a mental state called 'intuition'. However, as some have pointed out, his arguments for this conclusion are ineffective against the minimal conception of intuition adopted here (Devitt 2015), and they fail to undermine the usefulness of this conception for metaphilosophical debates (Nado 2016). Second, Cappelen and Deutsch have argued that debates about the role of intuitions in philosophical inquiry should be settled at least in part by empirical investigation. In keeping with their proposal, in what follows I offer empirical evidence for thinking that intuitions play epistemically significant roles in philosophy. In particular, I will focus on

\footnotetext{
7 See Brown (2017) for a similar argument.
} 
empirical findings from the burgeoning field of research known as the 'sources project' in experimental philosophy. ${ }^{8}$

Studies in the sources project aim to identify the cognitive processes that generate philosophical intuitions and to evaluate whether those cognitive processes are reliable (e.g., Nagel 2010; Fischer and Engelhardt 2016, 2019; Gerken and Beebe 2016). To date, most research in the sources project has focused on cognitive processes underwriting intuitions people have in response to paradigm philosophical thought-experiments (e.g., Gettier cases). However, another growing body of work in the sources project focuses instead on cognitive processes that generate intuitions that lead people to accept crucial premises in prominent philosophical arguments. For instance, in a number of studies, Fischer and Engelhardt (2016, 2019) have empirically investigated intuitions driving the 'Argument from Illusion'-an influential argument that has shaped philosophical debates about the nature of perception (Smith 2002). For current purposes, it will be useful to give a cursory description of these studies.

The Argument from Illusion begins from a verbal description of a perceptual experience in which an object appears to have properties it does not actually possess. For instance: 'A round coin will appear elliptical when viewed sideways'. Traditional formulations of the Argument from Illusion proceed from this verbal description to the negative conclusion that when viewing a coin sideways, one cannot be aware of the coin-which is, after all, round (Ayer 1963; Broad 1923; Russell 1912). This is then taken to motivate the conclusion that whatever one is aware of in this case, it is something other than the coin: namely, an elliptical sensedatum. ${ }^{9}$

Fischer and Engelhardt $(2016,2019)$ argue that the Argument from Illusion rests on an appeal to intuition. As they point out, proponents of this argument offer no explanation or argument in support of the negative conclusion that when viewing a coin sideways, one is not aware the round coin. This claim is instead immediately accepted as true and used to infer the argument's conclusion. Fischer and Engelhardt $(2016,2019)$ take this as indication that proponents of the argument (as well as readers) have an intuition that prompts them to accept this negative conclusion. In support of this proposal, they argue that this intuition can be traced to an automatic, unconscious cognitive process known as stereotype enrichment (Levinson 2000; Garrett and Harnish 2007). To illustrate the operations of this cognitive process, consider:

Tomato: She looked at the vibrant colour of the tomato.

Most people who read this claim will immediately judge that the protagonist was looking at a red tomato. Why do they leap to this conclusion if the protagonist could might as well have been looking at a green, orange, or a yellow tomato? One wellaccepted explanation for this is that people tend to inadvertently "enrich" the

\footnotetext{
${ }^{8}$ Pust (2019).

9 Contemporary reconstructions of this argument differ from these formulations (see, e.g., Smith, 2002). But, as Fischer and Engelhardt (2016) clarify, this does not matter for the arguments they develop.
} 
scenario in Tomato with their background information that tomatoes are stereotypically red (Atlas and Levinson 1981). For another illustration of the operations of processes of stereotype enrichment, consider the following case:

Surgeon: A boy and his father get into a severe car accident. The father dies, and the boy is taken to hospital. In the emergency room, the surgeon looks at the boy and says 'I can't operate on him. He's my son.'

A plausible explanation for why people tend to be stumped by this riddle is that the term 'surgeon' has a strong stereotypical association with the male gender (Giora 2003). This association prompts readers to "enrich" the scenario with the information that the surgeon must be the father, which conflicts with the statement that the father has died-thus giving rise to confusion.

Fischer and Engelhardt (2016, 2019) offer a similar psychological explanation for why proponents (and readers) of the Argument from Illusion leap from the description of how a round coin appears sideways to the judgement that one cannot be aware of the round coin in this case. To buttress this proposal, they provide a large body of empirical findings showing that most people who read claims of the sort 'x looks/appears/seems $F$ to $S$ ' inadvertently "enrich" such claims with the information that, typically, $\mathrm{S}$ will be inclined to judge that $\mathrm{x}$ is $\mathrm{F}$. And, likewise, when people read verbal descriptions of the sort 'a round coin viewed sideways appears elliptical', they will ordinarily "enrich" this with the information that the viewer is inclined to judge the object viewed to be elliptical. Fischer and Engelhardt (2016, 2019) point out that this gives rise to a conflict: whereas this enrichment prompts the conclusion that the object viewed is elliptical, the verbal description explicitly states that the coin is round. They argue that this conflict is what explains the intuition (i.e., the immediate, pre-theoretic, unreflective judgement) that the viewer cannot be aware of the round coin when viewing it sideways-which in turn facilitates the inference to the argument's conclusion.

Why is any of this relevant for discussions about the Irrelevance Claim? Here's why: if the findings from Fischer and Engelhardt $(2016,2019)$ are right that intuitions prompt people to accept the Argument from Illusion, then I contend that this intuition plays an epistemically significant role in philosophical inquiry-albeit not an evidential one. This is because, as already stated, the Argument from Illusion has heavily shaped philosophical debates about the nature of perception. For instance, many have taken this argument as motivation for sense-datum theories, and, concomitantly, as a challenge for naïve realist views of perception (see Smith 2002). Since philosophers expressly hold these positions as a result of accepting the Argument from Illusion, then their warrant for holding those positions depends at least in part on the epistemic standing of the intuitions that lead them to accept the Argument from Illusion. After all, if it turned out that this intuition was epistemically deficient, then this would presumably compel those philosophers to revise their support for sense-datum theories, and their reasons for rejecting naïve 
realist views. ${ }^{10}$ And note that this verdict does not require that this intuition play an evidential role in philosophical theorising. For, even if the intuition in question is not evidence for any philosophical position, and even if philosophers do not take it to be evidence for such, the fact that this intuition has shaped philosophical theorising about the nature of perception shows that it plays an epistemically significant role.

Furthermore, I contend that similar considerations apply to other cases in which intuitions have been found to influence whether people accept premises of philosophical arguments. For instance, Fischer and Engelhardt (2019) argue that processes of stereotype enrichment also underwrite judgements about crucial premises in the Argument from Hallucination. If these findings are right, then intuition driving this argument would presumably play an epistemically significant role in philosophical inquiry. This is because many philosophers have appealed to the Argument from Hallucination to defend philosophical positions about the nature of perception (Smith 2002). In line with the considerations above, I contend that the epistemic evaluation of those philosophers' warrant for holding such positions will rest at least in part on the epistemic standing of the intuition driving the Argument from Hallucination. And similarly, given recent findings suggesting that processes of stereotype enrichment shape people's interpretation and subsequent judgements about Gettier thought-experiments (see, e.g., Saint-Germier 2019), I contend that the intuitions such processes give rise to will also play an epistemically significant role in philosophy.

In sum, there is empirical evidence suggesting that at least some intuitions play epistemically significant roles in philosophy. These considerations effectively rebut the Orthogonality Claim and, by consequence, they undermine support the Irrelevance Claim. In light of these considerations I contend, pace Cappelen and Deutsch, that the study of intuitions is indeed relevant for an assessment of the methodology of philosophy.

\section{Conclusion}

I have argued that Cappelen and Deutsch fail to show that experimental findings about intuitions are irrelevant for an assessment of the methodology of philosophy (I dubbed this the 'Irrelevance Claim'). I first discussed a forceful objection to Cappelen and Deutsch's attempt to motivate the Irrelevance Claim. I then explained that this objection does not succeed as the arguments Cappelen and Deutsch advance purport to show that intuitions play no epistemically significant role whatsoever in philosophy (I called this the 'Orthogonality Claim'). I then argued that even under a charitable reading of their arguments, Cappelen and Deutsch fail to establish the Orthogonality Claim. Lastly, I discussed empirical evidence suggesting that intuitions play an epistemically significant role in philosophical

\footnotetext{
${ }^{10}$ Indeed, Fischer and Engelhardt (2016) argue that the intuition driving the Argument from Illusion is the product of a pernicious cognitive bias.
} 
inquiry - albeit not an evidential role. This suggests that the study of at least some intuitions is relevant for an assessment of the methodology of philosophy. In conclusion, I submit that Cappelen and Deutsch cannot vindicate the Irrelevance Claim, and that their arguments fail to refute the experimentalist challenge.

Acknowledgements Special thanks to Lisa Bastian, Jessica Brown, Ethan Landes, and an anonymous reviewer for this journal for comments on previous versions of this paper.

Open Access This article is distributed under the terms of the Creative Commons Attribution 4.0 International License (http://creativecommons.org/licenses/by/4.0/), which permits unrestricted use, distribution, and reproduction in any medium, provided you give appropriate credit to the original author(s) and the source, provide a link to the Creative Commons license, and indicate if changes were made.

\section{References}

Atlas, J. D., \& Levinson, S. C. (1981). It-clefts, informativeness and logical form: radical pragmatics (revised standard version). In: P. Cole (Ed.), Radical pragmatics, pp 1-62. Academic Press.

Ayer, A. J. (1963). The foundations of empirical knowledge. New York: Macmillan.

Bealer, G. (1998). A theory of concepts and concept possession. Philosophical Issues, 9, 261-301.

Broad, C. D. (1923). Scientific thought. Kegan Paul: Routledge.

Brown, J. (2017). The gettier case and intuition. In R. Borges, C. De Almeida, \& P. D. Klein (Eds.), Explaining knowledge: New essays on the gettier problem. Oxford: Oxford University Press.

Cappelen, H. (2012). Philosophy without intuitions. Oxford: Oxford University Press.

Cappelen, H. (2014). X-phi without intuitions? In A. R. Booth, D. P. Rowbottom (Eds.), Intuitions. Oxford University Press.

Cassam, Q. (2016). Vice epistemology. The Monist, 99(2), 159-180.

Chalmers, D. J. (2014). Intuitions in philosophy: A minimal defense. Philosophical Studies, 171(3), 535-544.

Climenhaga, N. (2017). Intuitions are used as evidence in philosophy. Mind, 127(505), 69-104.

Deutsch, M. (2015). The myth of the intuitive. Cambridge: The MIT Press.

Deutsch, M. (2017). Replies to commentators. Inquiry, 60(4), 420-442.

Devitt, M. (2015). Relying on intuitions: Where Cappelen and Deutsch go wrong. Inquiry, 58(7-8), $669-699$.

Fischer, E., \& Engelhardt, P. E. (2016). Intuitions' linguistic sources: Stereotypes, intuitions and illusions. Mind and Language, 31(1), 67-103.

Fischer, E., \& Engelhardt, P. (2019). Lingering stereotypes: Salience bias in philosophical argument. Mind and Language. https://doi.org/10.1111/mila.12249.

Garrett, M., \& Harnish, R. M. (2007). Experimental pragmatics: Testing for implicitures. Pragmatics \& Cognition, 15(1), 65-90.

Gerken, M., \& Beebe, J. R. (2016). Knowledge in and out of contrast. Nô̂s, 50(1), 133-164.

Giora, R. (2003). On our mind: Salience, context, and figurative language. Oxford: Oxford University Press.

Ichikawa, J. J. (2016). Intuitive evidence and experimental philosophy. In J. Nado \& J. R. Beebe (Eds.), Advances in experimental philosophy and philosophical methodology. London: Bloomsbury Academic.

Levinson, S. C. (2000). Presumptive meanings: The theory of generalized conversational implicature. Cambridge: MIT Press.

Lycan, W. G. (1986). Moral facts and moral knowledge. Southern Journal of Philosophy, 24(S1), 79-94.

Machery, E. (2017). Philosophy within its proper bounds. Oxford: Oxford University Press.

Nado, J. (2016). The intuition deniers. Philosophical Studies, 173(3), 781-800.

Nado, J. (2017). Demythologizing intuition. Inquiry, 60(4), 386-402. 
Nagel, J. (2010). Knowledge ascriptions and the psychological consequences of thinking about error. Philosophical Quarterly, 60(239), 286-306.

Pust, J. (2000). Intuitions as evidence. Abingdon: Routledge.

Pust, J. (2019). Intuition. In The Stanford encyclopedia of philosophy. Retrieved October 8, 2019 from https://plato.stanford.edu/archives/sum2019/entries/intuition/.

Russell, B. (1912). The problems of philosophy. New York: Barnes \& Noble.

Saint-Germier, P. (2019). Getting gettier straight: Thought experiments, deviant realizations and default interpretations. Synthese. https://doi.org/10.1007/s11229-019-02166-0.

Siegel, S., \& Silins, N. (2015). The epistemology of perception. In M. Matthen (Ed.), The Oxford handbook of philosophy of perception. Oxford: Oxford University Press.

Smith, A. D. (2002). The problem of perception. Cambridge: Harvard University Press.

Smithies, D. (2019). The epistemic role of consciousness. Oxford: Oxford University Press.

Stich, S., \& Tobia, K. (2016). Experimental philosophy and the philosophical tradition. In J. Sytsma \& W. Buckwalter (Eds.), A companion to experimental philosophy (pp. 5-21). Wiley.

Weatherson, B. (2014). Centrality and marginalisation. Philosophical Studies, 171(3), 517-533.

Weinberg, J. M. (2014). Cappelen between rock and a hard place. Philosophical Studies, 171(3), 545-553.

Williamson, T. (2007). The philosophy of philosophy. Oxford: Wiley-Blackwell.

Publisher's Note Springer Nature remains neutral with regard to jurisdictional claims in published maps and institutional affiliations. 